\section{USOS E ABUSOS DO FUNDO DE EMANCIPAÇÃO DE ESCRAVOS NA PROVÍNCIA DA BAHIA (1871-1888)}

DOI: $10.5935 / 2177-6644.20170011$

\author{
USES AND ABUSES OF THE SLAVE \\ EMANCIPATION FUND IN THE \\ PROVINCE OF BAHIA (1871-1888)
}

USOS Y ABUSOS DEL FONDO DE
EMANCIPACIÓN DE ESCLAVOS EN LA
PROVINCIA DE BAHÍA (1871-1888)

Ricardo Tadeu Caires Silva*

\begin{abstract}
Resumo: Neste texto discuto os usos e abusos da aplicação do fundo de emancipação de escravos na província da Bahia. Parte integrante da lei Rio Branco ou Ventre Livre (1871), o fundo estava entre as mais importantes medidas destinadas a promover uma transição lenta e gradual do trabalho escravo para o trabalho livre no Brasil. Seu objetivo era o de angariar recursos para promover a alforria dos escravos que não possuíam meios para indenizar seus senhores em troca da tão sonhada alforria. Em especial, o fundo visava alforriar prioritariamente os cativos que possuíssem família e, dentro desta, as mulheres e crianças. Aplicado tardiamente - devido aos entraves burocráticos e à vontade das autoridades locais -, o fundo de emancipação foi responsável pela libertação de 3.533 escravos na província da Bahia e cerca de 32 mil em todo o país. Ainda que estes números possam ser considerados modestos, este caminho legal se constituiu em mais uma opção para a conquista da liberdade de milhares de escravizados, contribuindo para a derrocada da escravidão no Brasil.
\end{abstract}

Palavras-chave: Escravidão. Fundo de emancipação. Bahia. Família escrava. Abolição.

\begin{abstract}
In this text I discuss the uses and abuses of the application of the slave emancipation fund in the province of Bahia. An integral part of the "Rio Branco" or "Ventre Livre" law (1871), the fund was among the most important measures designed to promote a slow and gradual transition from slave labor to free labor in Brazil. Its purpose was to raise funds to promote the manumission of slaves who had no means to compensate their masters in exchange for their long-awaited freedom. In particular, the fund was intended to give priority to the captives who had a family and, within the latter, women and children. Applied belatedly due to bureaucratic obstacles and the ill-disposed of local authorities, the emancipation fund was responsible for the release of 3,533 slaves in the province of Bahia and around 32,000 throughout the country. Although these numbers may be considered modest, this legal path has become another option for winning the freedom of thousands of slaves, contributing to the overthrow of slavery in Brazil.
\end{abstract}

Keywords: Slavery. Emancipation fund. Bahia. Slave family. Abolition.

Resumen: En este texto discuto los usos y abusos de la aplicación del fondo de emancipación de esclavos en la provincia de Bahía. Parte integrante de la ley Rio Branco o Ventre Livre (1871), el fondo estaba entre las más importantes medidas destinadas a promover una transición lenta y gradual del trabajo esclavo hacia el trabajo libre en Brasil. Su objetivo era recoger recursos para promover la manumisión de los esclavos que no poseían medios para indemnizar a sus señores a cambio de la tan soñada manumisión. En especial, el fondo visaba dar la manumisión prioritariamente a los cautivos que tenían familia y, dentro de esta, las mujeres y los niños. Aplicado tardíamente - debido a las barreras burocráticas y a la mala voluntad de las autoridades locales -, el fondo de emancipación fue responsable por la liberación de 3533 esclavos en la provincia de Bahía y cerca de 32000 en todo el país. Aún que estos números puedan ser considerados

\footnotetext{
* Docente nos Programas de Pós-Graduação em Formação Docente Interdisciplinar (PPIFOR) e Ensino de História (ProfHistória) na Universidade Estadual do Paraná - Unespar/Paranavaí. E-mail: rctadeu73@uol.com.br
} 
modestos, este camino legal se constituyó en una opción más para la conquista de la libertad de millares de esclavizados, contribuyendo para derrocar la esclavitud en Brasil.

Palabras clave: Esclavitud. Fondo de emancipación. Bahía. Familia esclava. Abolición.

\section{Introdução}

A Lei n. 2040, de 28 de setembro de 1871, mais conhecida como Lei Rio Branco ou Lei do Ventre Livre, foi criada com o fito de regular a transição do trabalho escravo para o trabalho livre no Brasil, sendo considerada, por muitos coevos, o golpe final no sistema escravista brasileiro (CONRAD, 1978; GEBARA, 1985; CHALHOUB, 1990). Além libertar os filhos de escravas nascidos a partir daquela data - medida, aliás, que lhe legou notoriedade -, a lei continha muitas outras determinações, tais como: o reconhecimento do direito do escravo em formar pecúlio para a sua alforria; a libertação dos escravos da nação; a matrícula especial dos escravos existente no império; e a criação de um fundo de emancipação destinado a libertar escravos - objeto das reflexões a seguir.

Formado a partir do produto de loterias, doações, taxas, impostos e multas, o fundo de emancipação tencionava libertar anualmente o maior número possível de escravos, cujos valores pudessem ser incluídos nos rendimentos arrecadados ${ }^{1}$. Para tal, os poderes locais fariam uma classificação dos cativos, estabelecendo quem teria prioridade nas libertações, conforme determinava o artigo 27 do Decreto $\mathrm{n}^{\circ} 5.135$, de 13 de novembro de 1872:

Famílias;

Indivíduos.

$\S 1^{\circ}$. Na libertação por família preferirão:

Os cônjuges que forem escravos de diferentes senhores;

Os cônjuges que tiverem filhos nascidos livres em virtude da lei e menores de 08 anos;

Os cônjuges que tiverem filhos menores de 21 anos;

Os cônjuges com filhos menores escravos;

As mães com filhos menores escravos;

Os cônjuges sem filhos menores. (Coleção das Leis do Império do Brasil de 1872, p. 1059).

Assim, o fundo de emancipação despontava como uma das alternativas para a libertação dos cerca de um milhão e meio de escravos existentes no país, segundo mais

\footnotetext{
${ }^{1}$ Ver o artigo $3^{\circ}$ da lei n. 2.040 de 28 de setembro de 1871. Coleção das leis do império do Brasil de 1872, Rio de janeiro: Typografia Nacional, 1872.
} 
tarde informaria o censo realizado por orientação da própria lei de 1871. Segundo o historiador Fabiano Dauwe, contudo, o fundo não fora concebido para libertar escravos em massa; ou seja, não era a principal arma no combate à escravidão. Pelo contrário, era destinado a uma parcela bem específica da população escrava:

[...] os objetivos do fundo de emancipação de escravos eram totalmente diferentes dos das demais formas de libertação, como também o eram as regulamentações que o regiam. A estrutura do fundo, como vimos, não foi pensada para se libertarem escravos em massa: os recursos não eram abundantes o suficiente, nem havia limitações aos preços dos cativos. Por outro lado, os critérios de libertação estabelecidos para o fundo terminaram por atender a um grupo muito específico - principalmente famílias, que tinham preferência sobre escravos solteiros e tendiam a ocupar quase todas as poucas vagas destinadas à emancipação (DAUWE, 2004, p. 108).

Seguindo a diretriz mais geral da lei, o fundo visava atingir preferencialmente as famílias escravas. Tal estratégia, por sua vez, estava em perfeita consonância com a política gradualista de transição para o trabalho livre levada a cabo pelo governo imperial, cuja lógica previa o aproveitamento dos escravos masculinos, adultos e solteiros - mais aptos ao trabalho nas lavouras -, em detrimentos de mulheres, idosos e crianças (GEBARA, 1985). Daí privilegiar as famílias e, dentre estas, aquelas cujos escravos possuíssem pecúlio para complementar o valor de suas liberdades. Malgrado esse caráter seletivo, o fundo foi visto pela comunidade escrava como uma alternativa a mais na consecução da tão sonhada liberdade.

\section{O funcionamento do fundo de emancipação}

Entretanto, como bem frisou Robert Conrad (1978, p. 137), o fundo de emancipação só veio a funcionar tardiamente, tendo as primeiras libertações ocorrido após cinco anos de ter sido criado, ou seja, a partir de 1876. Isso aconteceu, em parte, pela recusa dos funcionários do governo em participar gratuitamente das juntas de classificação e também pela falta de informação acerca dos procedimentos a serem seguidos para que as libertações ocorressem. A esse respeito, José Pereira dos Santos Neto salienta "[...] a década de 1870 como a época da montagem e de aparelhamento da estrutura administrativa necessária para a aplicação dos recursos públicos e das primeiras experiências dos integrantes das juntas com o serviço" (NETO, 2012, p. 48). Para além 
da questão de organização da estrutura administrativa de operação do fundo, havia, porém, a ingerência dos poderes locais, muitas vezes desinteressados no funcionamento correto da lei. Nesse sentido, e ainda de acordo com o autor,

[...] os trabalhos relativos ao fundo de emancipação eram dirigidos (ou boicotados) nas vilas pelo alto comando dos postos da administração local, o topo da hierarquia da esfera pública municipal. Geralmente pessoas oriundas das famílias e dos grupos dominantes, com níveis altos de rendas, provavelmente com instrução, sobretudo o promotor, bacharel em direito, e bem relacionados em suas localidades com a classe senhorial, pois eram oriundas do seu meio social (NETO, 2012, p. 54).

O fundo também não ficou imune de fraudes. Segundo Robert Conrad,

[...] para fazerem com que seus escravos menos valiosos fossem elegíveis para venda através do fundo, os seus donos, em certos casos, organizavam casamentos entre idosos e os muito jovens, entre escravos inúteis ou incorrigíveis e pessoas livres, que eram induzidas a tal por dinheiro (CONRAD, 1978, p. 139-140).

Mesmo, porém, com os problemas apontados, o fundo de emancipação foi responsável pela libertação de mais de 32 mil cativos nas 21 províncias do Império, os quais custaram aos cofres públicos mais de 27 mil contos de réis (DAUWE, 2004, p. 7).

Quando do início de sua aplicação, a província da Bahia ainda ocupava o terceiro lugar no número de cativos do Império, com 173.639 escravizados. Ficava atrás apenas das províncias do Rio de Janeiro, que possuía 304.744 escravos, e Minas Gerais, detentora de 333.438 cativos (BARICKMAN, 1998-1999, p. 194). Por isso, os preparativos para sua efetivação não passaram desapercebidos de escravos, abolicionistas e também de boa parte da classe senhorial.

Assim como nas demais partes do Império, na Bahia, a primeira aplicação dos recursos do fundo só ocorreu cinco anos após a sua criação, ou seja, a partir de 1876. Naquele ano, haviam sido libertados

[...] 158 escravos nos seguintes municípios baianos: Alagoinhas (13), Brejo Grande (9), Cayru (1), Tapera (9) Santa Isabel (6), Capim Grosso (4), Barra (5), Camamu (5), Caetité (20), Lençóis (12), Valença (5), Taperoá (4), Itaparica (7), Marahú (1), Juazeiro (4), Monte Santo (4), Sento Sé (1), Itapicuru (9), Jacobina (9), Remanso (8), Jaguaripe (4), Soure (1), Belmonte (2) e Abadia (4) (NETO, 2012, p. 48). 
No ano seguinte foram realizadas mais algumas libertações, como as ocorridas em fevereiro de 1877, na Vila de Carinhanha, no extremo oeste da província. Nessa ocasião, foram libertados os escravos Rufino, Policarpa e Inácia. O curioso dessas libertações é que todos os cativos ofereceram pecúlio para completar a quantia pela qual foram avaliados, possibilidade que estava prevista em lei (cf. Decreto n. 5.135, de 13 de novembro de 1872). Policarpa, de cor cabra, de 45 anos, por exemplo, era solteira, sabia os ofícios de cozinheira e engomadeira, e depositou 150 mil réis para completar os 700 mil réis em que fora avaliada. Já Rufino, de 43 anos, também de cor cabra e solteiro, era vaqueiro, e depositou 543 mil réis para abater da soma de 1 conto de réis em que fora estimado. Por fim, a parda Inácia, de 28 anos, lavadeira, havia dado 200 mil réis dos 800 mil estipulados (APEBA, 1877).

Esses dados, como sugere Sylvana Brandão de Vasconcelos para a província de Pernambuco, demonstram que, nesse primeiro momento, os escravos libertados pelo fundo de emancipação parecem ter sido, de preferência, aqueles que possuíam algum pecúlio para completar seus valores. Analisando as listas de escravos classificados pelo fundo, a autora constatou que a maioria dos cativos escolhidos não possuía idade avançada e ainda eram produtivos. Para Vasconcelos (1996, p. 96), essa constatação põe em xeque algumas conclusões mais tradicionais da historiografia brasileira acerca do processo de transição do trabalho escravo para o trabalho livre, que insistem em acentuar o caráter fraudulento da lei do Ventre Livre, afirmando que os escravos inscritos nos fundos de emancipações eram apenas os domésticos, idosos ou incapacitados para o trabalho e com preços inflacionados. (CONRAD, 1976).

\section{Os escravos e o fundo de emancipação}

Isto leva a crer que, para muitos cativos, o fundo de emancipação se apresentava como mais uma possibilidade para a conquista da liberdade. Ou seja, caso a negociação cotidiana falhasse, caso o escravo não tivesse um pecúlio suficiente para intentar na Justiça uma ação de liberdade, restava ainda a possibilidade de recorrer ao fundo, na esperança de conseguir completar esse valor. Em alguns casos, o fundo parecia ser a única alternativa de libertação para as famílias desprovidas de recursos, como a da escrava Eusébia (AMRC, 1885). 
Casada com um homem livre, Eusébia dera luz muitos filhos e, aos 44 anos, era mãe dos pardos Demétrio (de 18 anos), Francelina (de 16), Bento (de 15) e Cristina (de 13 anos), todos pertencentes ao capitão Joaquim José de Magalhães. Era mãe ainda dos ingênuos ${ }^{2}$ Antônio, Cecília, Narcisa e Francisco, já libertos pela lei de 1871 - condição que ajudava nos critérios classificatórios do fundo. A julgar pela numerosa prole, Eusébia e seu marido tinham poucas condições econômicas para sustentá-los, sendo exígua a possibilidade de formarem um pecúlio suficiente para se libertarem. A inclusão no fundo de emancipação era, para essa família, a alternativa mais razoável para se livrarem do julgo de um senhor que, ao que tudo indica, era muito intransigente.

Morador no Arraial de Paramirim, pertencente à Vila de Minas do Rio de Contas, o capitão Joaquim Magalhães parecia pouco disposto a dar sua parcela de contribuição para a abolição da escravidão, pois, em 1885, em plena campanha abolicionista, dificultou o máximo que pôde a libertação dos escravos, teimando em não concordar com os valores propostos pelo coletor geral. Ao que parece, Magalhães estava mais preocupado em contabilizar os prejuízos que teria quando perdesse a propriedade dos referidos cativos, o que naturalmente forçou o juiz a fazer um arbitramento judicial. ${ }^{3}$ As autoridades judiciais de Rio de Contas pareciam estar dispostas a agir em favor da liberdade, pois, nesse mesmo ano, o fundo de emancipação também realizou o arbitramento de Felicidade, de sua filha Virgínia e de seu neto Firmino, por não concordar com os valores propostos pelo proprietário dos cativos. A avaliação aconteceu à revelia de Aprígio Ribeiro de Magalhães e estipulou a liberdade de Felicidade em 180 mil réis, enquanto que Virgínia e seu filho foram libertados por $300 \mathrm{mil}^{4}$

Em quase uma década de aplicação, o fundo de emancipação libertou 3.533 escravos na Bahia, conforme podemos ver na tabela abaixo:

\footnotetext{
${ }^{2}$ Por ingênuo(s) entende-se aquele indivíduo que nasce livre, ou seja, sem vínculos com a escravidão. Tal era a condição das crianças nascidas a partir da Lei de 1871.

${ }^{3}$ Não foi possível saber se o fundo pagou a libertação da família de Eusébia, pois o processo está incompleto.

${ }^{4}$ As idades de Virgínia e Firmino não são mencionadas na ação, embora este último fosse ingênuo. Cf. AMRC. Escravos. Ação de arbitramento. Ano: 1885. Felicidade era casada com o liberto Manoel.
} 
Tabela 01: Escravos libertados pelas cotas do Fundo de Emancipação

\begin{tabular}{|c|c|c|c|c|c|c|}
\hline Ano & Cota & Receita & $\begin{array}{l}\text { Governo } \\
\text { Geral }\end{array}$ & $\begin{array}{l}\text { Governo } \\
\text { Provincial }^{5}\end{array}$ & $\begin{array}{l}\text { Pecúlios } \\
\text { dos } \\
\text { Escravos }\end{array}$ & $\begin{array}{l}\text { Escravos } \\
\text { Libertados }\end{array}$ \\
\hline 1877 & $1^{\mathrm{a}}$ & $423: 852 \$ 779$ & Idem & & $31: 984 \$ 433$ & $\mathrm{n} /$ consta \\
\hline $1881 / 83$ & $2^{\mathrm{a}}$ & $381: 907 \$ 130$ & $\mathrm{n} / \mathrm{c}$ & & $52: 032 \$ 661$ & $\mathrm{n} /$ consta \\
\hline $1883 / 84$ & $3^{a}$ & 190: $953 \$ 565$ & $\mathrm{n} / \mathrm{c}$ & & $27: 755 \$ 877$ & $\mathrm{n} /$ consta \\
\hline $1884 / 85$ & $4^{\mathrm{a}}$ & $250: 000 \$ 000$ & Idem & & $25: 302 \$ 061$ & $\begin{array}{l}1.705 \\
1884\end{array}$ até \\
\hline $1885 / 86$ & $5^{\mathrm{a}}$ & 150: $203 \$ 535$ & 150:000\$000 & & $24: 875 \$ 733$ & $\mathrm{n} /$ consta \\
\hline $1885 / 86$ & $6^{\mathrm{a}}$ & 200:000\$000 & Idem & & $26: 144 \$ 106$ & $\mathrm{n} /$ consta \\
\hline $1885 / 87$ & $7^{\mathrm{a}}$ & $189: 723 \$ 224$ & $130: 000 \$ 000$ & $59: 723 \$ 224$ & $22: 632 \$ 305$ & $\mathrm{n} /$ consta \\
\hline & Total & $1.786: 640 \$ 273$ & & 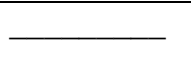 & $210: 727 \$ 176$ & 3.533 \\
\hline
\end{tabular}

Fonte: Relatório dos Presidentes da Província da Bahia (1877-1887).

As cidades e vilas que mais alforriaram escravos a partir das verbas do fundo foram: Cachoeira e Curralinho (389), Salvador (329), Santo Amaro (150), Feira de Santana (144), Santo Antônio da Barra (137), São Francisco do Conde (134), Nazaré (121) Maragogipe (104), Alagoinhas (98), Caetité (92), Purificação (89) e Minas do Rio de Contas (74) (Cf. FALA com que o Exm ${ }^{\circ}$ Sr. Conselheiro João Capistrano Bandeira de Mello..., 1887, p. 131-134). Cabe aqui salientar que a maior parte dessas localidades se encontrava na região do Recôncavo açucareiro, onde se concentrava a maior parte dos escravos baianos. Segundo cálculos apresentados por Bert Barickman e com base na matrícula geral de 1872-1873, ali viviam entre 70 e 80 mil escravos; ou seja, quase metade dos escravos de toda a província (BARICKMAN, 2003, p. 333).

Como foi dito anteriormente, a distribuição das cotas do fundo de emancipação ocorreu de forma lenta e desordenada devido à ineficiência das juntas de classificação. $\mathrm{Na}$ verdade, as cotas passaram a ser distribuídas com mais intensidade a partir do ano de 1883 (DAUWE, 2004). Prova disso é que ainda em 1884 havia resíduos das quatro primeiras cotas que não haviam sido utilizados (Cf. FALA com que o Exm $^{\circ}$. Sr. Conselheiro Pedro Luiz Pereira de Sousa..., 1884, p. 67). No começo do ano seguinte, ao

\footnotetext{
${ }^{5}$ Em 14 de maio 1881 foi aprovada a Lei Provincial n. 2.146, que criou o fundo de emancipação provincial, porém os valores arrecadados durante a vigência da lei, ou seja, nos exercícios de 1881-1882 e 1882-1883, só foram utilizados durante a $7^{\mathrm{a}}$ cota, a partir do ano de 1885 .
} 
comentar o andamento dos trabalhos para a aplicação do fundo, o presidente Esperidião Eloy de Barros Pimentel informava que

[...] este ramo do serviço público tem tido regular execução nesta província, não tanto quanto fora para desejar-se; por isso que algumas delongas tem havido, causadas pela falta de reunião de algumas Juntas Classificadoras nas épocas marcadas e pelas dúvidas que se tem suscitado por parte das mesmas Juntas, ás quais o Governo dá-se pressa em resolver, no intuito de proceder-se às libertações com a brevidade possível, em observância das recomendações do Governo Imperial. (FALA com que o $\mathrm{Ilm}^{\circ}$. e Exm ${ }^{\circ}$. Desembargador Esperidião Eloy de Barros Pimentel..., 1885, p. 90).

Segundo ele, contudo, conquanto houvesse alguns contratempos, a distribuição da $4^{\mathrm{a}}$ cota estava quase cumprida; a $5^{\mathrm{a}}$ estava bastante adiantada, e os trabalhos para a distribuição da $6^{\mathrm{a}}$ estavam sendo iniciados, conforme fala do Desembargador Esperidião Eloy de Barros Pimentel. Ainda em maio de 1885 também foi iniciada a distribuição da $7^{\mathrm{a}}$ cota e, segundo o sucessor de Barros Pimentel, o conselheiro Theodoro Machado Freire Pedreira da Silva, os trabalhos estavam sendo feitos com a regularidade possível, sendo que

[...] somente falta proceder-se a libertação pela referida cota nos municípios de Santo Amaro, Nazaré, Santo Antônio de Jesus, Almas, Taperoá, Rio das Éguas, Prado, Trancoso e no de Santarém, onde não foi aplicada a cota por ser insuficiente para a libertação do escravo classificado em primeiro lugar pela respectiva junta. (RELATÓRIO, 1887, p. 128).

A distribuição dessas últimas cotas praticamente coincidiu com a fase mais radical do movimento abolicionista (1885-1888), fato que contribuiu para que o fundo de emancipação fosse bastante acionado tanto pelos escravos como pelos senhores (BRITO, 2003; SILVA, 2007). Esse movimento é notório e bastante preciso nas vilas onde a $7^{\mathrm{a}}$ cota ainda estava por ser distribuída, a exemplo de Santo Amaro, no Recôncavo Baiano.

\section{Os senhores e o fundo de emancipação}

Num inusitado documento arrolado como uma ação de liberdade, descobri que nada menos do que 54 cativos residentes naquela localidade estavam se valendo do casamento, associado à apresentação de pecúlio, para melhorar suas classificações na 
lista de contemplados pelo fundo entre os anos de 1885 e 1887 (APEBA, 1888). O uso dessa estratégia, aliás, foi constatado também em outras regiões da província, a exemplo das vilas de Vila Viçosa e Porto Alegre e Orobó (BRITO, 2004, p. 50), bem como em outras partes do Império (DAUWE, 2007).

O mais surpreendente é que, na maioria dos casos que analisei, os escravos foram auxiliados por seus próprios senhores, os quais certamente queriam receber indenizações pelas manumissões dos mesmos e continuarem a manter as relações paternalistas com os futuros libertos. Vale lembrar que, naquele momento, com o crescimento da campanha abolicionista, a contestação ao cativeiro estava sendo feita com base em argumentos que dispensavam qualquer tipo indenização aos proprietários, como as ações judiciais movidas a partir dos argumentos de filiação desconhecida, da falta de matrícula e da importação ilegal para o Brasil após a lei de 1831 (CHALHOUB, 1990; SILVA, 2000). Nesse sentido, concordo com a afirmação da historiadora Isabel Cristina Ferreira dos Reis, segundo a qual:

[...] um pouco antes de meados da década de oitenta, já havia se tornando consenso entre a classe proprietária que poderia ser vantajoso alforriar seus cativos pelo Fundo de Emancipação, pois assim estaria garantido o pagamento do valor do escravo pelo Estado, hajam vistas os intensos debates sobre como os escravocratas poderiam ser ressarcidos pela perda da propriedade de seus cativos no momento em que a abolição definitiva do trabalho servil acontecesse (REIS, 2007, p. 227).

Assim, não foram poucos os senhores que, temendo perder seus escravos, incentivaram-nos ao casamento, como também ofereceram pecúlio para que tivessem maiores chances de se libertar mais rapidamente. Muitos, além de guardarem as economias de seus cativos, foram pessoalmente à Coletoria interceder para que fossem privilegiados na classificação, como o fez dona Adelaide da Silva Lisboa, que, desejando:

[...] alforriar pelo fundo de emancipação seu escravo Terêncio, de cor cabra, com 32 anos de idade, casado com mulher livre, o qual se acha matriculado na coletoria desta cidade com $\mathrm{n}^{\circ} 539$ da matrícula geral e 01 da relação apresentada em $22 / \mathrm{nov} / 86$, e $\mathrm{n}^{\circ} 13.926$ da matrícula anterior, vem requerer a Vs. ${ }^{a}$ incluí-lo no número dos que tiverem que receber o benefício da lei, visto ter direito na $1^{\mathrm{a}}$ classe por ser casado. Em benefício do seu escravo oferece a quantia de 50 mil réis. Santo Amaro, 19/ abr/1887 (APEBA, 1888). 
Os escravos, por seu turno, não perderam a oportunidade e aquiesceram à oportunidade de mostrar que eram formalmente casados ou ainda de legitimar as uniões consensuais em que viviam e, em outros casos, se casar e assim obter maiores chances de conseguir a alforria mais rapidamente. Foi o que fizeram o casal de escravos Guilherme e Olímpia Pires, pertencentes ao Barão de Pirajá. Em 5 de maio de 1885, eles apresentaram a certidão de seu casamento, realizado em maio de 1868, e do qual nasceram os "filhos ingênuos de nomes Maria Gregória, Maria Sofia, Geminiano, Onofre, Herculano e Arteliano", e, de posse de um pecúlio de 100 mil réis, pediram para serem classificados a fim de se libertarem. E também o escravo Romão do Prado, casado com Maria da Trindade, mulher livre, que depositou 100 mil réis que possuía em poder de sua senhora para melhor ser classificado. Romão foi libertado pela $7^{\mathrm{a}}$ cota do fundo em 15 de abril de 1887.

Em muitas situações, essa estratégia deu certo para ambas as partes, pois, assim como nos casos acima, em muitos outros as libertações indenizatórias realmente se concretizaram. O padre Manoel Alexandrino do Prado, vigário da freguesia de Nossa Senhora da Purificação, realizou boa parte desses casamentos, e adotou ele mesmo tal estratégia para libertar seu escravo João Patrício, casado com a mulher livre Maria Catarina de Jesus, em cerimônia realizada em janeiro de 1885; e Praxedes Monteiro, casado em fevereiro desse mesmo ano com a também livre Juliana Ferreira de Souza. Praxedes pertencia a seu sobrinho Joaquim Inácio Monteiro, que estava na Europa, e de quem era curador. A alforria de ambos foi efetivada em maio de 1887.

O mais curioso é que os escravos que não conseguiram se libertar pelo fundo acabaram sendo mais tarde alforriados por seus próprios senhores ou mesmo pela Lei Áurea, em maio de 1888. Então, muitos voltaram à Coletoria Geral para recolher, com juros, os pecúlios que haviam depositado. Foi o caso de Clementina Loureiro, escrava de Francisco da Silva Loureiro, liberta por seu senhor em abril de 1887 e que anteriormente havia depositado 100 mil réis no fundo para sua libertação; e de Emília, escrava de Mateus Muniz Fiúza, que, em maio de 1885, havia recolhido 120 mil réis e, em setembro do ano seguinte, mais 50 mil, mas que em 20 de fevereiro de 1888 foi liberta por seu senhor. Feitas as contas, levando-se em conta "juros de 5\% ao ano do mesmo capital contados de 7/maio/85 a 21/fev/88", ela recebeu 189\$306 réis; ou ainda de Marciana, que em 13 de maio de 1886 recolheu 125 mil réis para sua liberdade, mas que em julho de 1887 foi libertada por sua senhora, dona Maria Cândida de Magalhães Castro. Sua 
restituição foi de $143 \$ 500$. Os exemplos são vários e os valores dos pecúlios bem aproximados: Basília, Hermínia, Marcelina, Maria Florência, Maria da Paixão, Maria, Constança Severina, Virgínia, Clementina, Luiz e sua mulher Maria de Pinho, Alexandrina, Guilherme, Carolina, etc. Para estes, a vida de liberto começou com um pouco mais de alento.

\section{Considerações finais}

Embora tenha sido tardiamente aplicado e considerado como um instrumento ineficaz pelos abolicionistas e por muitos historiadores (CONRAD, 1978; COSTA, 1998), o fundo de emancipação possibilitou a libertação de centenas de escravos e certamente auxiliou no desgaste da legitimidade da escravidão. Conforme salientou Fabiano Dauwe, o fundo possuía um caráter ambíguo, pois:

[...] ao mesmo tempo em que garantia ao escravo o direito à libertação, retirando do senhor parte do direito de decidir quais escravos seriam mais merecedores desse "prêmio", o Estado indenizava o senhor por essas liberdades, reconhecendo a propriedade sobre o escravo como um direito (DAUWE, 2004, p. 127).

Para os escravos, porém, ansiosos pela conquista da liberdade, essa ambiguidade fazia parte de uma escolha consciente. Ao utilizarem a estratégia do casamento para melhor se situarem nas listas de classificação do fundo, os escravos não só deram visibilidade às relações afetivas e às uniões formais e consensuais em que viviam, como também aumentaram as chances de conseguir a alforria mais rapidamente. Afinal, para eles, a família escrava sempre significou a esperança de dias melhores.

\section{Referências}

BARICKMAN, Bart Jude. Até a véspera: o trabalho escravo e a produção de açúcar nos engenhos do Recôncavo Baiano (1850-1881). Afro-Ásia, Salvador, n. 21-22, 1998-1999.

Um contraponto baiano. Açúcar, fumo, mandioca e escravidão no Recôncavo (1780-1860). Rio de Janeiro: Civilização Brasileira, 2003.

BRITO, Jaílton Lima. A abolição na Bahia (1870-1888). Salvador: CEB, 2003.

CASTILHO, Celso; COWLING, Camila. Bancando a liberdade, popularizando a política: abolicionismo e fundos locais de emancipação na década de 1880 no Brasil. Afro-Ásia, Salvador, n. 47, 2013. 
CHALHOUB, Sidney. Visões da liberdade: uma história das últimas décadas da escravidão na Corte. São Paulo: Companhia das Letras, 1990.

CONRAD, Robert Edgar. Os últimos anos da escravatura no Brasil 1850/1888. Rio de Janeiro: Civilização Brasileira, 1978.

COSTA, Emília Viotti da. Da senzala à colônia. 4. ed. São Paulo: UNESP, 1998.

DAUWE, Fabiano. A libertação gradual e a saída viável. Os múltiplos sentidos da liberdade pelo fundo de emancipação de escravos. (Mestrado em História). Universidade Federal Fluminense, Niterói, 2004.

FLORENTINO, Manolo; GÓES, José Roberto. A paz das senzalas. Famílias escravas e tráfico atlântico. Rio de Janeiro (1790-1850). Rio de Janeiro: Civilização Brasileira, 1997.

FONSECA, Luís Anselmo da. A escravidão, o clero e o abolicionismo. Recife, PE: Fundaj/Editora Massangana, 1988.

GEBARA, Ademir. O mercado de trabalho livre no Brasil, 1871-1888. São Paulo: Brasiliense, 1986.

MATTOS, Hebe Maria. Das cores do silêncio: os significados da liberdade no sudeste escravista (Brasil, século XIX). Rio de Janeiro: Nova Fronteira, 1998.

NETO, José Pereira de Santana. A alforria nos termos e limites da lei: o fundo de emancipação na Bahia (1871-1888). (Mestrado em História). Universidade Federal da Bahia, Salvador, 2012.

REIS, Isabel Cristina Ferreira dos. A família negra no tempo da escravidão: Bahia, 1850-1888. (Doutorado em História). Universidade Estadual de Campinas, Campinas, 2007.

Histórias de vida familiar e afetiva de escravos na Bahia do século XIX. Salvador: CEB, 2001.

SILVA, Ricardo Tadeu Caires. Os escravos vão à Justiça. A resistência escrava através das ações de liberdade. (Mestrado em História). Universidade Federal da Bahia, Salvador, 2000.

Caminhos e descaminhos da abolição: escravos, senhores e direitos nas últimas décadas da escravidão (1850-1888). (Doutorado em História). Universidade Federal do Paraná, Curitiba, 2007.

SLENES, Robert. Na senzala uma flor: esperanças e recordações na formação da família escrava, Brasil, sudeste, século XIX. Rio de Janeiro: Nova Fronteira, 1999.

VASCONCELOS, Sylvana Maria Brandão de. Ventre livre, mãe escrava: a reforma social de 1871 em Pernambuco. Recife, PE: Ed. UFPE, 1996.

\section{Fontes}

APEBA. Seção Judiciária Ação de liberdade. Class: 84/2989/27. Local: Carinhanha. Ano: 1877.

APEBA. Seção Judiciária. Ação de liberdade. Class: 34/1202/13. Local: Santo Amaro. Ano: 1888 . 
AMRC. Escravos. Ação de liberdade. Eusébia x Joaquim José de Magalhães. Ano: 1885. Coleção das leis do império do Brasil de 1872, artigo $3^{\circ}$ da lei n. 2.040, de 28 de setembro de 1871.

FALA com que o Exm ${ }^{\circ}$. Sr. Conselheiro Pedro Luiz Pereira de Sousa abriu a $1^{\text {a }}$ sessão da 23 ${ }^{a}$ Legislatura da Assembléia Provincial da Bahia em 9 de abril de 1884. Bahia. Typographia do Diário da Bahia, 1884, p. 67.

FALA com que o $\operatorname{Exm}^{\circ}$. Sr. Conselheiro João Capistrano Bandeira de Mello abriu a $2^{\text {a }}$ sessão da $26^{\text {a }}$ Legislatura da Assembléia Provincial da Bahia no dia 4 de outubro de 1887. Bahia. Typographia da Gazeta da Bahia, 1887, p.131-134.

FALA com que o $\mathrm{Ilm}^{\circ}$. e Exm ${ }^{\circ}$. Desembargador Esperidião Eloy de Barros Pimentel abriu a $2^{\mathrm{a}}$ sessão da $25^{\mathrm{a}}$ Legislatura da Assembléia Provincial da Bahia em $1^{\circ}$ de maio de 1885. Bahia. Typographia do Diário da Bahia, 1885, p. 90.

RELATÓRIO com que o Exm ${ }^{\circ}$ Sr. Desembargador Aurélio Ferreira Espinheira passou a administração da província ao $\mathrm{Exm}^{\circ}$. Sr. Conselheiro João Capistrano Bandeira de Mello no dia 11 de outubro de 1886. Bahia. Typographia de Olavo da França Guerra, 1887, p. 128.

Recebido em: 24 de abril de 2017. Aprovado em: 05 de junho de 2017. 